\title{
Anti- and pro-apoptotic activities of baculovirus and Drosophila IAPs in an insect cell line
}

\author{
Alex J. Harvey ${ }^{1}$, Hatem Soliman ${ }^{1}$, William J. Kaiser ${ }^{1}$ and \\ Lois K. Miller ${ }^{1,2,3}$ \\ ${ }^{1}$ Department of Genetics, The University of Georgia, Athens, Georgia 30602, \\ USA \\ 2 Department of Entomology, The University of Georgia, Athens, Georgia 30602, \\ USA \\ 3 corresponding author: Lois K. Miller, tel: (706) 542-2294; fax: (706) 542- \\ 2279; e-mail: miller@bscr.uga.edu
}

Received 29.4.97; revised 4.6.97; accepted 14.7.97

Edited by D.R. Green

\begin{abstract}
The anti-apoptotic activities of two baculovirus IAPs, OpIAP and CpIAP, were directly compared with that of two Drosophila IAPs, DIAP1 and DIAP2, in the same insect cell line, SF-21 cells. Like OpIAP and CpIAP, DIAP1 inhibited actinomycin Dinduced apoptosis and apoptosis induced by Doom. Removal of the RING finger of DIAP1 reduced but did not eliminate its anti-apoptotic activity. DIAP2 was unable to inhibit actinomycin-D induced apoptosis but was able to partially inhibit Doominduced apoptosis. The baculoviral BIR and RING finger regions, when separated, were unable to block apoptosis induced by actinomycin D or Doom. Instead, the BIR regions of OpIAP and CpIAP as well as the RING finger regions of CpIAP and DIAP1 induced apoptosis. Thus, there were significant differences in the manner in which the different domains of the viral and cellular homologues of IAPs interacted with the components of the pathways regulating apoptosis in SF-21 cells.
\end{abstract}

Keywords: iap; baculovirus; apoptosis; $\bmod (\operatorname{mdg} 4)$; Doom; DIAP1

Abbreviations: IAP, inhibitory apoptosis protein; DIAP, Drosophila IAP homologue; BIR, baculovirus IAP repeat; AcMNPV, Autographa californica nuclear polyderosis virus; BmNPV, Bombyx mori nuclear polyhedrosis virus; ICE, interleukin $1 \beta$-converting enzyme; CpGV, Cydia pomonella granulosis virus; OpMNPV, Orgyia pseudotsugata nuclear polyhedrosis virus; SF-21, Spodoptera frugiperda cell line; NAIP, neuronal apoptosis inhibitory protein; HA, hemagglutinin; CAT, chloramphenicol acetyltransferase; ECL, enhanced chemiluminescence

\section{Introduction}

Multicellular organisms possess a cellular defense mechanism that results in the directed suicide, known as programmed cell death and/or apoptosis, of cells that may be deleterious to the organism (reviewed by Arends and Wyllie, 1991; Wyllie et al, 1980). Cells targeted for apoptosis include those infected with viruses, extra cells formed during development, and cells that have suffered irreparable DNA damage and/or are dividing unchecked (reviewed by Steller, 1995; Thompson, 1995). These cells will actively end their existence by a series of morphological and biochemical processes including proteolysis of specific proteins, cell surface blebbing, breakdown of chromatin structure, and apoptotic body formation.

The obvious importance of apoptosis to cellular biology has led to a search for apoptotic regulatory genes. Disease-linked genetic aberrations, developmental mutations, and viruses have been the source of many apoptotic regulatory genes. Viruses are a particularly rich source of apoptotic regulatory genes because of the need to counteract the host cell apoptotic defense mechanism. Viral apoptotic genes have become invaluable in probing the cellular apoptotic circuitry and identifying cellular homologues or counterparts. The baculoviruses, a family of large DNA-containing insect viruses, have contributed two classes of anti-apoptotic genes, p35 and the iaps. P35, which is encoded by the nuclear polyhedrosis viruses of Autographa californica (AcMNPV) and Bombyx mori (BmNPV) can block apoptosis induced by a variety of stimuli in insects, mammals, and nematodes (Clem et al, 1991; Hay et al, 1994; Kamita et al, 1993; Rabizadeh et al, 1993; Sugimoto et al, 1994). P35 binds to and inactivates members of the family of interleukin- $1 \beta$-converting enzyme (ICE)-like cysteine proteases (Bump et al, 1995; Xue and Horvitz, 1995). The ability of P35 to function in many diverse cellular backgrounds has made it an important probe for the detection of ICE-like proteases in uncharacterized apoptotic pathways.

The baculovirus IAPs, Cp-IAP and Op-IAP, were isolated from Cydia pomonella granulosis virus (CpGV) and Orgyia pseudotsugata nuclear polyhedrosis virus (OpMNPV), respectively (Birnbaum et al, 1994; Crook et al, 1993). These IAPs were identified by their ability to substitute for P35 in blocking AcMNPV-induced apoptosis in the SF-21 cell line, which is derived from the lepidopteran insect species, Spodoptera frugiperda, the fall armyworm. The IAPs have no structural similarity to the P35 protein but instead have two types of zinccoordinating motifs, the baculovirus IAP repeat (BIR) and a carboxyl-terminal RING finger, both of which are required for anti-apoptotic activity (Clem and Miller, 1994). RING finger motifs are found in a number of proteins involved in such diverse cellular activities as transcription, DNA repair and cell proliferation (reviewed by Freemont, 1993) whereas the BIR motif is unique to IAPs and is tandemly repeated in the amino-terminal and central portions of the protein (reviewed by Clem et al, 1996). In addition to blocking baculovirus-induced apoptosis, OpIAP and CpIAP can block actinomycin D-induced apoptosis in SF-21 cells 
in the absence of other viral factors, indicating that the IAPs interact directly with cellular apoptotic pathways (Clem and Miller, 1994). The baculovirus IAPs also can inhibit apoptosis in developing Drosophila eyes and mammalian cells (Duckett et al, 1996; Hay et al, 1995; Uren et al, 1996).

Humans, mice and Drosophila possess cellular IAP homologues which have two or three BIRs and, in most cases, a RING finger at the carboxyl-terminus (Duckett et al, 1996; Hay et al, 1995; Liston et al, 1996; Rothe et al, 1995; Roy et al, 1995; Uren et al, 1996). A Drosophila IAP homologue, DIAP1, was identified in a screen for mutations that enhance the effect of reaper and hiddependent apoptosis in the developing eye (Hay et al, 1995). A second Drosophila IAP homologue, DIAP2 (also called DIAP, DILP, or DIHA) was identified by sequence homology (Duckett et al, 1996; Hay et al, 1995; Liston et al, 1996; Uren et al, 1996). Ectopic expression of DIAP1 or DIAP2 inhibits reaper or hid-induced apoptosis in the developing eye. DIAP1 encodes two BIRs and DIAP2 encodes three BIRs and both DIAPs have a carboxylterminal RING finger. The full-length DIAP1 inhibits apoptosis in the developing Drosophila eye but inhibition is enhanced if the RING finger region is removed from the coding sequence. Expression of the RING finger region alone enhances apoptosis in the developing Drosophila eye. Likewise, a human IAP homologue, C-IAP1, is not able to inhibit apoptosis in the developing Drosophila eye unless its RING finger region is removed (Hay et al, 1995). The neuronal apoptosis inhibitory protein (NAIP), identified as having a possible role in spinal muscular atrophy in humans, lacks a RING finger motif in its coding sequence and blocks apoptosis in mammalian cell lines (Roy et al, 1995).

Doom, a Drosophila protein which can induce apoptosis in insect cells, was identified by its ability to interact with the baculovirus IAPs (Harvey et al, 1996). Doom is encoded by one of five known alternative mRNAs of the Drosophila mod(mdg4) gene. Mod(mdg4) has been implicated in the regulation of gene expression and chromatin structure but has not yet been linked to the regulation of apoptosis in Drosophila (Dorn et al, 1993; Gerasimova et al, 1995). Doom, when expressed in insect cells, rapidly induces apoptosis which can be blocked by OpIAP, CpIAP and P35 (Harvey et al, 1996). The DoomIAP interaction is mediated through the IAP BIR region (defined as the region encompassing both BIR motifs) and does not require the IAP RING finger. When coexpressed with IAP truncations encoding only the BIR region, Doom can still induce apoptosis. Therefore binding of the BIR region alone to Doom is insufficient to block Doominduced apoptosis. The BIR region must be physically attached to the RING finger region in order to block Doominduced apoptosis, suggesting that the IAPs interact with additional, unknown factors through the RING finger region.

The differential dependence of the members of the IAP family on the presence of the RING finger and the structural diversity of the BIR region led us to investigate the individual roles of the BIR and RING finger regions. We compared the influence of the BIR and RING finger regions of DIAP1, DIAP2, and the baculovirus IAPs, OpIAP and CpIAP, on cellular and Doom-induced apoptotic pathways in SF-21 cells. We found that, when separated, the baculovirus BIR and RING finger regions cannot block apoptosis and have an opposite effect, the induction of apoptosis. Removal of the RING finger region from DIAP1 and DIAP2 reduced the anti-apoptotic activity of these proteins, although the BIR region of DIAP1 retained some anti-apoptotic activity.

\section{Results}

\section{Construction and expression of IAP truncations}

Full length baculovirus and Drosophila IAPs were expressed in SF-21 cells under control of the heat-inducible heat shock promoter, HSP70 (Figure 1). The BIR and RING finger regions of OpIAP, CpIAP, and DIAP1 and the BIR region of DIAP2 were manipulated so that they could be expressed separately (Figure 1). Because antibodies to the IAPs are not available, the full-length IAPs and IAP truncations, except for DIAP1RING, were tagged at the amino-terminus with the hemagglutinin (HA) epitope (designated Epi-tag) to allow detection of expressed proteins (Figure 1).

Attempts to express untagged and tagged DIAP1 from the first methionine of the cDNA sequence were unsuccessful. A DIAP1 construct which was Epi-tagged at the first methionine (Figure $2 \mathrm{~A}$ ) rapidly degraded into small peptides upon expression (data not shown). DIAP1 encodes a second methionine which is at the $\mathrm{N}$-terminus end of the first BIR repeat and is flanked by sequences which fit the consensus for Drosophila start codons, suggesting that it can be used as a start codon (Figure $2 A)$. We also noticed that PBSDIAP1-ORF and pGMRDIAP1-BIR (described as pBSDIAP1 $\beta$-ORF and pGMRDIAP $1 \beta$-BIR in this paper) provided by $B$ Hay lacked the coding sequence for the first 34 amino acids of the DIAP1 cDNA. Accordingly all untagged DIAP1 and DIAP1BIR clones used in this paper started from the second methionine and are designated DIAP1 $\beta$ and DIAP1 $\beta$-BIR (Figure 1). To construct EpiDIAP1 $\beta$ and EpiDIAP1 $\beta$-BIR, the second methionine was replaced with the HA epitope tag (Figures 1 and 2A). Untagged and Epi-tagged DIAP2s were successfully constructed and expressed using its first methionine (Figure 1).

To express the proteins, the plasmids were transiently transfected into SF-21 cells followed by heat-shock treatment; a procedure which does not induce apoptosis in SF-21 cells transfected with control plasmids (Clem and Miller, 1994). To confirm expression of Epi-tagged proteins, cells transfected with Epi-tagged constructs were harvested at $4 \mathrm{~h}$ post-heat shock followed by immunoblot analysis. All Epi-tagged proteins were expressed at detectable levels and migrated at their expected molecular weights during polyacrylamide electrophoresis (Figure $2 \mathrm{~B}$ and $\mathrm{C}$ ). Levels of expression were similar for all constructs except for Epi-tagged CpIAP RING (EpiCpRING) which was expressed at approximately tenfold lower levels. 


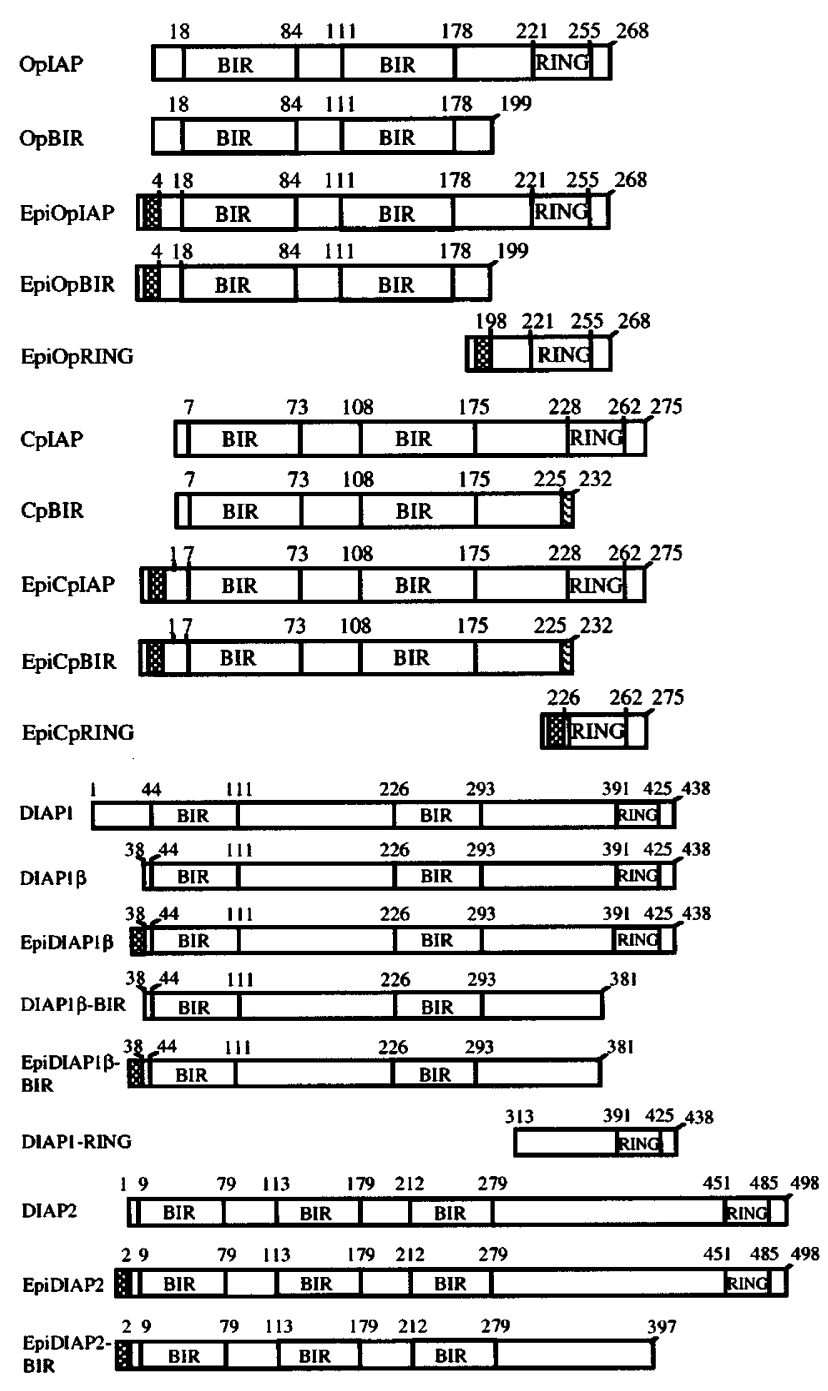

Figure 1 Schematic representations of untagged and Epi-tagged IAPs and their truncations. Numbers indicate amino acid positions relative to the fulllength sequences of their open reading frames. The HA epitope tags are denoted by the checkered regions. BIR and RING denotes the baculovirus iap repeat and RING finger regions, respectively. The altered reading frame after the frameshift in the CpBIR constructs is denoted by the zig-zag pattern. Note that the scale of the DIAPs is compressed relative to the baculovirus IAPs

\section{The BIR and RING finger regions of the baculovirus IAPs do not block actinomycin D- induced apoptosis}

The viability of SF-21 cells treated with actinomycin D can be increased by prior transfection with OpIAP and CpIAPencoding plasmids, confirming the role of IAPs in inhibition of apoptosis (Clem and Miller, 1994). We therefore compared the abilities of the Epi-tagged IAPs and IAP truncations to inhibit apoptosis induced by actinomycin $D$. To ensure that equivalent amounts of plasmid DNA were used in each transfection, chloramphenicol acetyltransferase (CAT)-expressing plasmids were added to some transfection mixtures. The coexpression of CAT with the IAP proteins had no effect on any of the observed activities
A

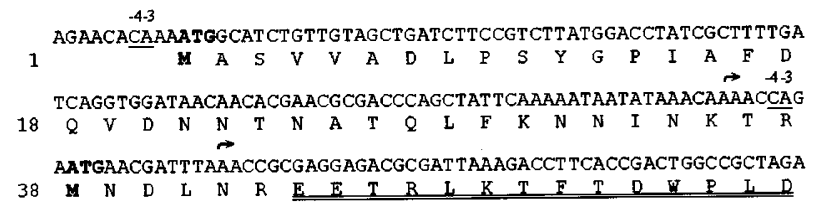

B

C

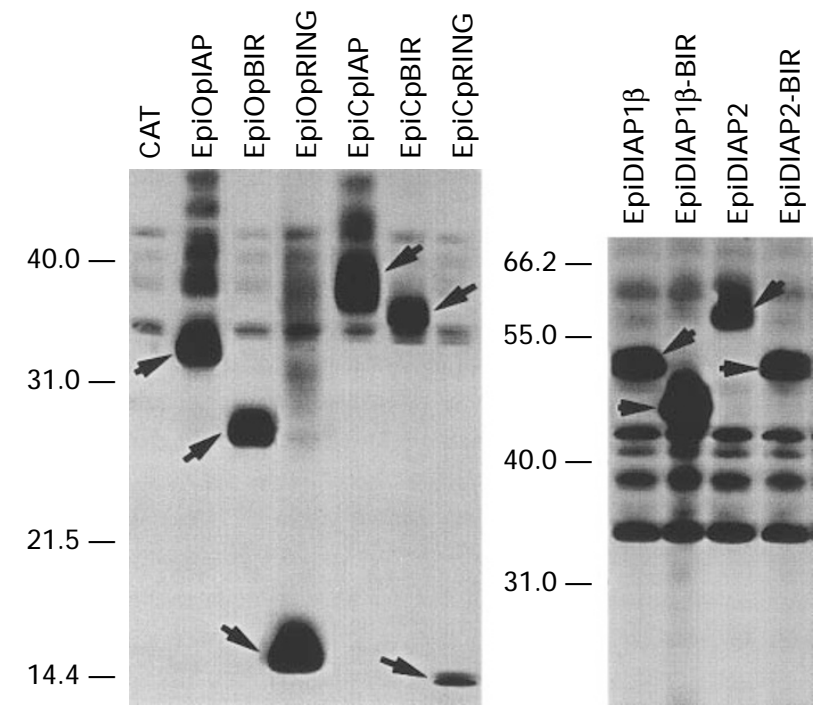

Figure 2 Alternate start codons of DIAP1 and expression of Epi-tagged IAPs. (A) The sequence of the amino terminus of DIAP1 is shown. The first and second methionines and start codons are in bold. The -4 and -3 positions are single underlined. The start of the first BIR is double underlined. The first arrow indicates the start of the nucleotide sequence of untagged DIAP $1 \beta$ clones. The second arrow indicates the position at which the DIAP1 $\beta$ sequence was fused to the HA epitope tag. (B) and (C) Expression vectors encoding the indicated proteins were transfected into SF-21 cells. At $4 \mathrm{~h}$ postheat shock, cellular lysates were harvested and analyzed by immunoblot analysis using anti-HA polyclonal antiserum. Positions of Epi-tagged proteins are indicated by the arrows. Positions of molecular weight standards (in kilodaltons) are shown

(data not shown). Untagged OpIAP and the Epi-tagged IAPs, EpiOpIAP and EpiCpIAP, inhibited actinomycin Dinduced apoptosis at similar levels, indicating that the Epitagged IAPs functioned in a comparable manner to untagged OpIAP (Figure 3). The levels of protection are approximately twofold higher than previously described (Clem and Miller, 1994) because of a higher transfection efficiency achieved using lipofectin instead of calcium phosphate during the transfection procedure. Cells expressing Epi-tagged or untagged BIR regions of CpIAP and OplAP showed no protection against actinomycin D, indicating that the BIR regions alone cannot inhibit apoptosis induced by actinomycin D (Figure 3). Expression of the Epi-tagged RING finger regions of the IAPs also afforded no protection for SF-21 cells treated with actinomycin D (Figure 3). To determine if the BIR and RING finger regions can work when expressed in trans, OpBIR and EpiOpRING or CpBIR and EpiCpRING were cotransfected into SF-21 cells. These cells also showed no resistance to induction of apoptosis by actinomycin $D$, 
indicating that the BIR and RING finger regions of the baculovirus IAPs must be covalently linked in order to function (Figure 3).

\section{The BIR region of the baculovirus IAPs induce apoptosis}

In the course of these experiments, we noticed that cells expressing the baculovirus BIR regions exhibited cell surface blebbing and apoptotic body formation in the absence of actinomycin D. To confirm the induction of apoptosis by the BIR regions, we assayed for chromatin degradation as indicated by nucleosomal laddering. Both OpBIR and CpBIR, and their Epi-tagged counterparts, induced detectable nucleosomal ladders by $8 \mathrm{~h}$ post-heat shock (Figure 4A, left panel). The induction of laddering by tagged BIRs leveled out at $8 \mathrm{~h}$ while the laddering induced by untagged BIRs increased up to $24 \mathrm{~h}$, indicating that the epitope tag was interfering with the ability of BIRs to induce apoptosis over an extended period of time (Figure 4A, right panel). This effect could be a result of reduced cellular concentrations of tagged BIRs relative to untagged BIRs either due to decreased expression or protein stability. We cannot compare the cellular levels of tagged and untagged IAPs because our efforts to raise antibodies against the baculovirus IAPs have been unsuccessful. In some experiments, laddering induced by $\mathrm{CpBIR}$ at $8 \mathrm{~h}$ was more prominent or equal to the intensity of laddering observed at $24 \mathrm{~h}$ (Figures $4 \mathrm{~A}$ and $5 \mathrm{~A}, \mathrm{~B}$ ).

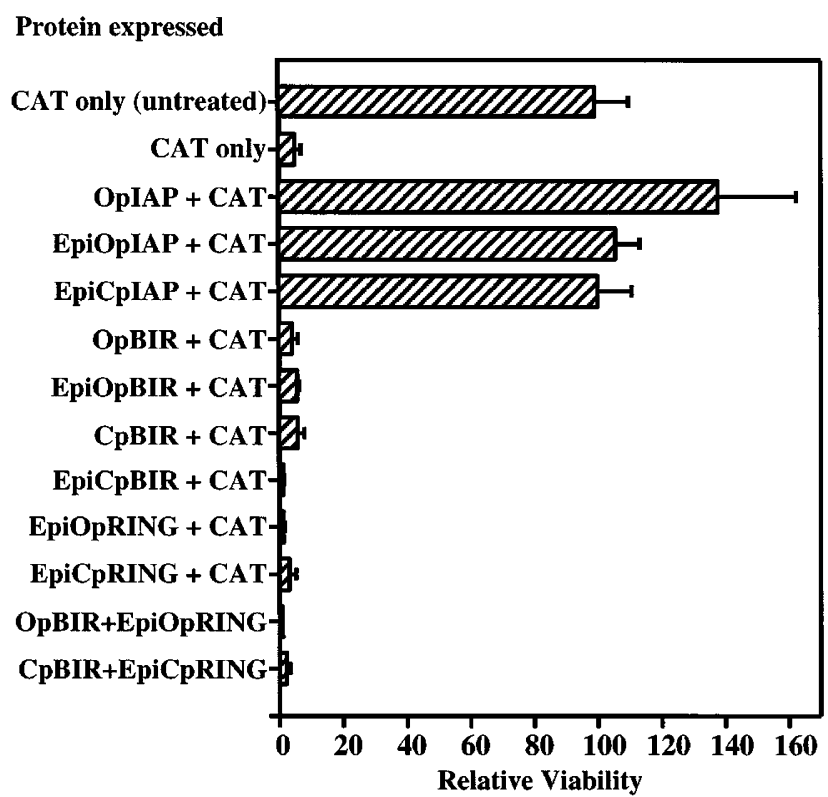

Figure 3 Full-length baculovirus IAPs but not truncations protect against actinomycin D-induced apoptosis. SF-21 cells expressing the indicated proteins were treated with actinomycin $D$ at $4 \mathrm{~h}$ post-heat shock. CATexpressing plasmids were used to balance concentrations of plasmids transfected into cells. Cell viability was determined $20 \mathrm{~h}$ later by the trypan blue exclusion assay. Viability was compared to untreated chloramphenicol acetyltransferase (CAT)-transfected cells counted at the time of actinomycin D treatment
Although OpBIR and CpBIR both induced cytopathic effects indicative of apoptosis, there were noticeable differences in the timing and morphology of membrane blebbing. OpBIR and EpiOpBIR induced membrane blebbing which was most prominent at $24 \mathrm{~h}$ post-heat shock (Figure 4B, panels 2 and 3). CpBIR induced two distinct morphological changes, both of which were most prominent at 8 to $12 \mathrm{~h}$ post-heat shock. Most cells affected by CpBIR displayed membrane blebbing similar to that observed for OpBIR-treated cells (Figure 4B, panel 4). A smaller percentage of CpBIR-transfected cells underwent extensive elongation of the entire cell and did not exhibit any signs of membrane blebbing (Figure 4B, panel 5). Some OpBIR cells also demonstrated elongation but these were far less frequent than that observed for CpBIR (data not shown). EpiCpBIR-transfected cells behaved like CpBIR-transfected cells except that the cytopathic effects were most prominent at $24 \mathrm{~h}$ post-heat shock (Figure 4B, panel 6).

BIR-induced cell death was not widespread until $24 \mathrm{~h}$ after heat shock induction, at which time unaffected cells had divided and obscured the reduction in cell number. Therefore counts of viable cells as determined by the trypan blue assay did not accurately reflect the extent of apoptosis observed by visible membrane blebbing and nucleosomal laddering. To obtain a quantitative estimate of BIR-induced apoptosis, the percentage of cells demonstrating blebbing and elongation was determined at 8 and $24 \mathrm{~h}$ post-heat shock by microscopic inspection. OpBIR and EpiOpBIR induced blebbing in $60 \%$ and $20 \%$ of cells remaining at $24 \mathrm{~h}$ post-heat shock, respectively (Figure 4C). CpBIR and EpiCpBIR induced apoptosis in 30\% and $15 \%$ of cells remaining at $8 \mathrm{~h}$ post-heat shock, respectively (Figure $4 \mathrm{C}$ ). CpBIR blebbing was reduced to $15 \%$ of remaining cells at $24 \mathrm{~h}$ post-heat shock, presumably because most CpBIR-transfected cells had completely disintegrated at that time.

\section{Full-length IAPs and P35 can inhibit BIR-induced apoptosis}

To further confirm that the cellular changes induced by the BIRs are indicative of apoptosis, the ability of full-length IAPs and P35 to inhibit BIR-induced apoptosis was tested. At $8 \mathrm{~h}$ post-heat shock both P35 and the IAPs were able to block OpBIR and CpBIR-induced apoptosis as judged by the nucleosomal ladder assay (Figure 5A). P35 and the IAPs were also able to block BIR-induced membrane blebbing and cell elongation (data not shown). Cotransfection of the RING finger constructs with the BIR constructs had no effect or slightly increased the extent of apoptosis (Figure 5A and B). CpIAP blocked OpBIR-induced apoptosis and OpIAP blocked CpBIR-induced apoptosis (Figure 5A).

At $24 \mathrm{~h}$ post-heat shock, BIR-induced apoptosis was still completely blocked by P35 but the ability of the IAPs to block BIR-induced apoptosis was significantly reduced (Figure 5B). OpIAP partially inhibited OpBIR and CpBIRinduced apoptosis while CpIAP was totally ineffective at $24 \mathrm{~h}$ post-heat shock. Western analysis indicated that the cellular concentrations of the Epi-tagged IAPs at $24 \mathrm{~h}$ had 


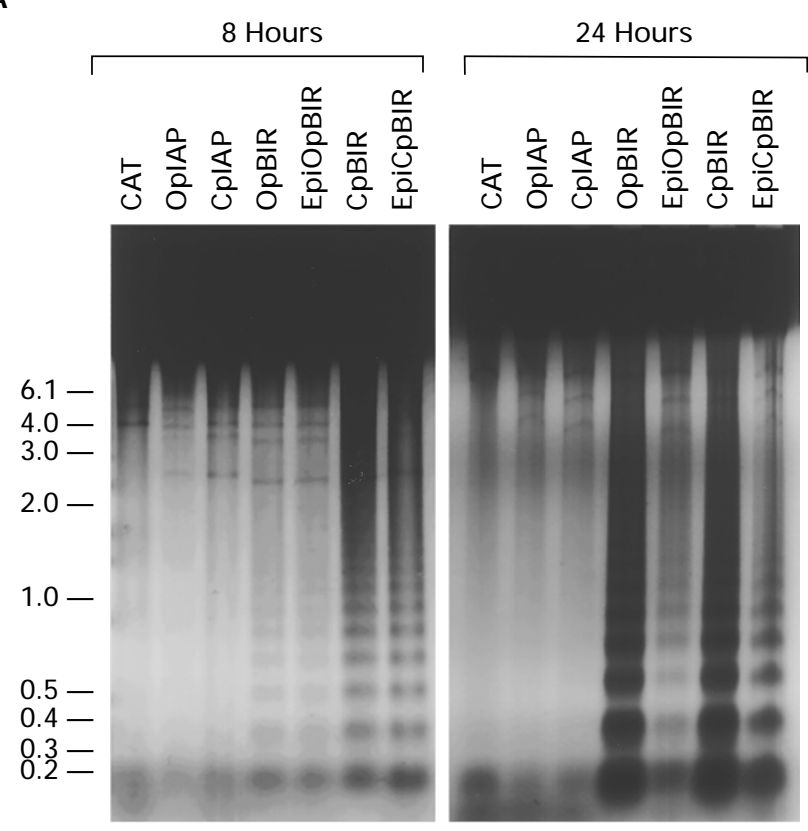

B
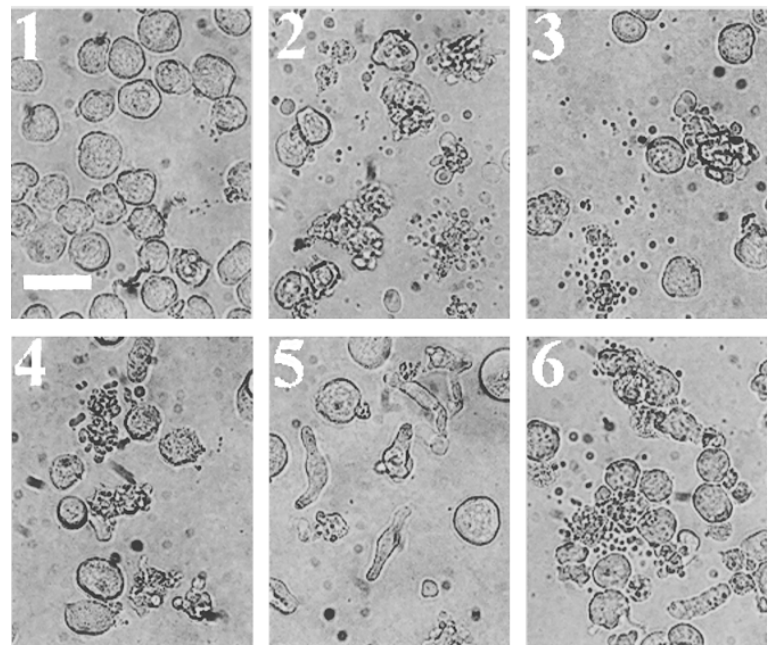

C

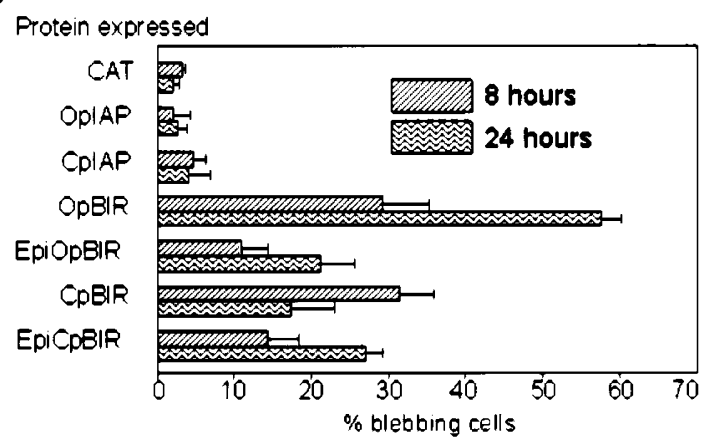

Figure 4 Baculovirus BIRs induce apoptosis. (A) SF-21 cells were transfected with plasmids expressing the protein indicated above each lane under heat shock promoter control. Cellular DNA was harvested at 8 and $24 \mathrm{~h}$ post-heat shock, separated by agarose gel electrophoresis, stained with ethidium bromide and visualized on a fluorimager. Positions of molecular declined to approximately $10 \%$ of the levels observed at 4 and $8 \mathrm{~h}$ post-heat shock whereas the concentration of Epitagged P35 at $24 \mathrm{~h}$ was reduced to $50 \%$ of the levels observed at $8 \mathrm{~h}$ post-heat shock (Figure 5C). Therefore, due to either differences in expression or stability, the cellular levels of P35 during the experiment were more uniform than OpIAP or CpIAP and could account for its ability to provide long-term protection against BIR-induced apoptosis. Although we were not able to compare the influence of the epitope tag on cellular concentrations of IAPs because antiserum specific to the IAPs was not available, untagged and tagged IAPs both protected at $8 \mathrm{~h}$ but not at $24 \mathrm{~h}$, suggesting that the epitope tag did not affect the expression or stability of the IAPs. P35 also did not seem to be affected by the epitope tag as tagged and untagged P35 protected as well at $24 \mathrm{~h}$ post-heat shock (data not shown).

\section{CpRING induces apoptosis}

Transfection of EpiCpRING into SF-21 cells induced nucleosomal laddering that was detectable at $24 \mathrm{~h}$ postheat shock (Figure 6A). EpiCpRING induced both membrane blebbing and cell elongation similar to that observed for CpBIR (Figure 6B, panel 3). EpiCpRINGinduced cytopathic effects were visible in approximately $25 \%$ of the cells present at $24 \mathrm{~h}$ post-heat shock (Figure $6 \mathrm{C})$. EpiOpRING did not induce any signs of apoptosis (Figure 6A and $\mathrm{B}$, panel 2). The EpiOpRING construct used encoded an extra 20 amino acids not present in EpiCpRING (Figure 1), therefore we created a second EpiOpRING construct which was more similar in size to EpiCpRING. The second EpiOpRING construct also did not induce any signs of apoptosis (data not shown) indicating the extra 20 amino acids was not responsible for lack of EpiOpRING activity.

The ability of P35 and full-length IAPs to block EpiCpRING-induced apoptosis was similar to that described for BIR-induced apoptosis. While at $8 \mathrm{~h}$ EpiCpRING-induced nucleosomal laddering was barely detectable, some EpiCpRING-induced cytopathic effects were visible except in cells cotransfected with P35 or CplAP (data not shown). At $24 \mathrm{~h}$ post-heat shock, EpiCpRING-induced laddering and blebbing was significantly reduced by P35 (Figure $6 \mathrm{~A}$ and $\mathrm{C}$ ). CpIAP had no effect on EpiCpRING-induced laddering (Figure 6A) and reduced blebbing moderately (Figure $6 \mathrm{C}$ ).

weight standards (in kilobases) are shown. (B) SF-21 cells were heat shocked at $\mathrm{t}=\mathrm{O}$ following cotransfection with plasmids expressing the following proteins under heat shock promoter control. Photographs were taken at the indicated times post-heat shock: chloramphenicol acetyltransferase (CAT), $24 \mathrm{~h}$ (panel 1); OpBIR plus CAT, $24 \mathrm{~h}$ (panel 2); EpiOpBIR plus CAT, $24 \mathrm{~h}$ (panel 3); CpBIR plus CAT, $8 \mathrm{~h}$, two different fields (panels 4 and 5); EpiCpBIR plus CAT, $24 \mathrm{~h}$ (panel 6); Scale bar $25 \mu \mathrm{m}$. (C) The percentage of cells demonstrating blebbing and elongation induced by expression of the indicated constructs was determined at 8 and $24 \mathrm{~h}$ post-heat shock as described in Materials and Methods 


\section{DIAP1-RING induces apoptosis and DIAP1 $\beta$ partially inhibits actinomycin D-induced apoptosis}

Expression of full-length DIAP1 $\beta$ or DIAP1 $\beta$-BIR did not produce any signs of apoptosis while DIAP1-RING induced both nucleosomal laddering (Figure 7A) and membrane blebbing (data not shown). DIAP1 $\beta$-BIR was able to partially inhibit DIAP1-RING-induced apoptosis (Figure 7A). Fulllength DIAP2 and Epi-tagged DIAP2-BIR, EpiDIAP2-BIR, did not produce signs of apoptosis in SF-21 cells (data not shown). The RING finger region of DIAP2 was not expressed separately in this study.

A

8 Hours Post-Heat Shock

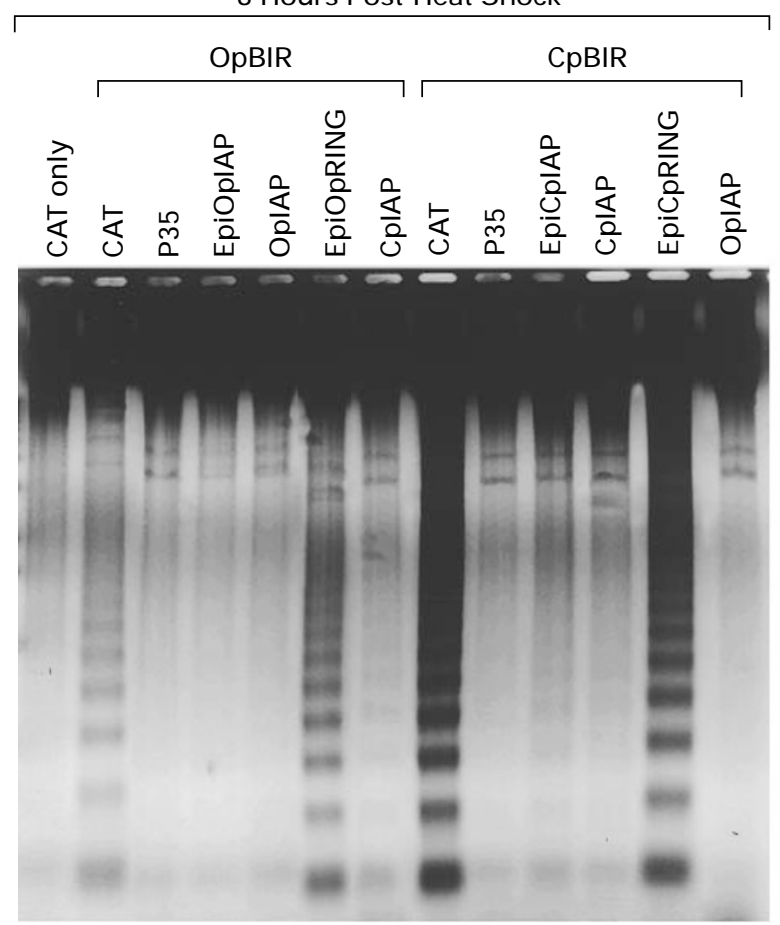

The DIAP1 $\beta$ and DIAP2 constructs were tested for their ability to inhibit actinomycin D-induced apoptosis. DIAP1 $\beta$ protected $30 \%$ of SF-21 cells from actinomycin D-induced apoptosis (Figure 7B). Other constructs, including the untagged or tagged DIAP1 $\beta$-BIR, untagged and tagged fulllength DIAP2, and tagged DIAP2-BIR, showed marginal levels of protection that were not significantly above the background protection afforded by expression of CAT (Figure 7B). EpiDIAP1 $\beta$ did not protect against actinomycin Dinduced apoptosis as determined by counting of trypan-blue stained cells $20 \mathrm{~h}$ after addition of actinomycin D (Figure 7B) but some protection was observed in cells at 4 or $8 \mathrm{~h}$ (data
B
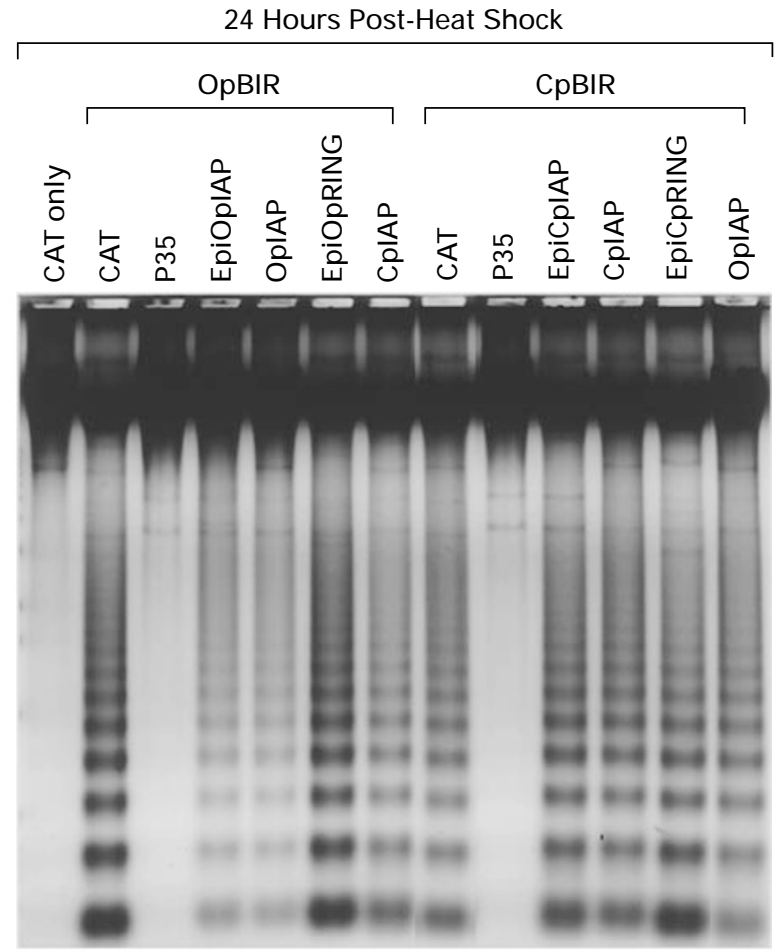

C

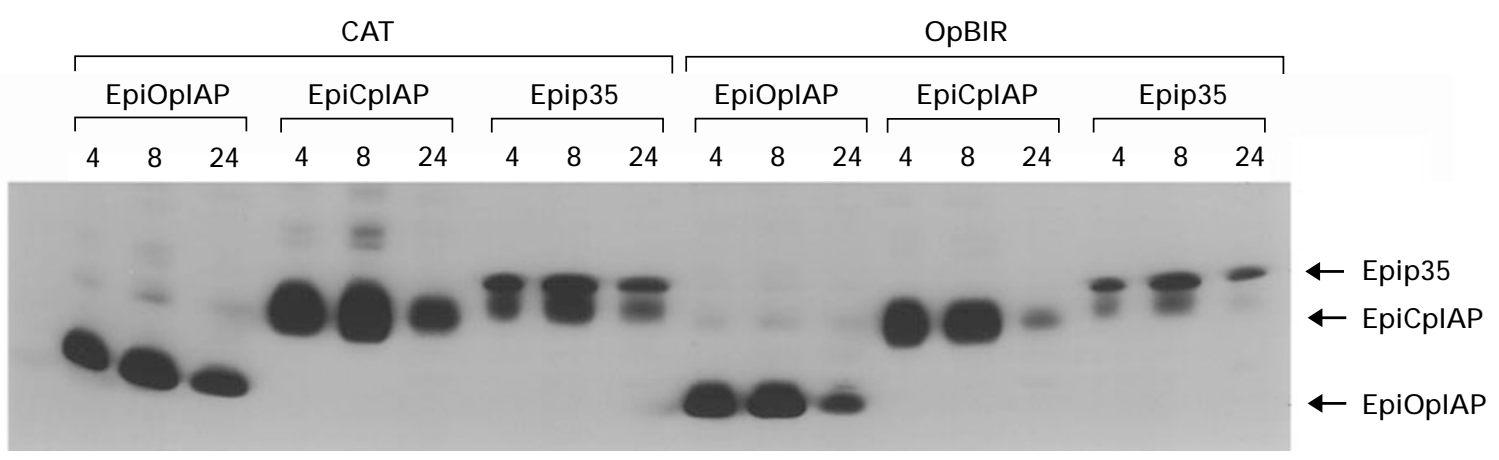

Figure 5 Inhibition of BIR-induced apoptosis by p35 and full-length IAPs. (A) and (B) SF-21 cells were transfected with plasmids expressing the protein(s) indicated above each lane under heat shock promoter control. Cellular DNA was harvested at $8(\mathbf{A})$ and 24 (B)h post-heat shock, separated by agarose gel electrophoresis, stained with ethidium bromide and visualized on a fluorimager. (C) SF-21 cells coexpressing CAT or OpBIR with EpiOpIAP, EpiCpIAP or Epip35 were harvested at 4,8 and $24 \mathrm{~h}$ post-heat shock. Cellular lysates were analyzed by immunoblot analysis using anti-HA polyclonal antiserum. Positions of Epitagged proteins are indicated by the arrows 
A
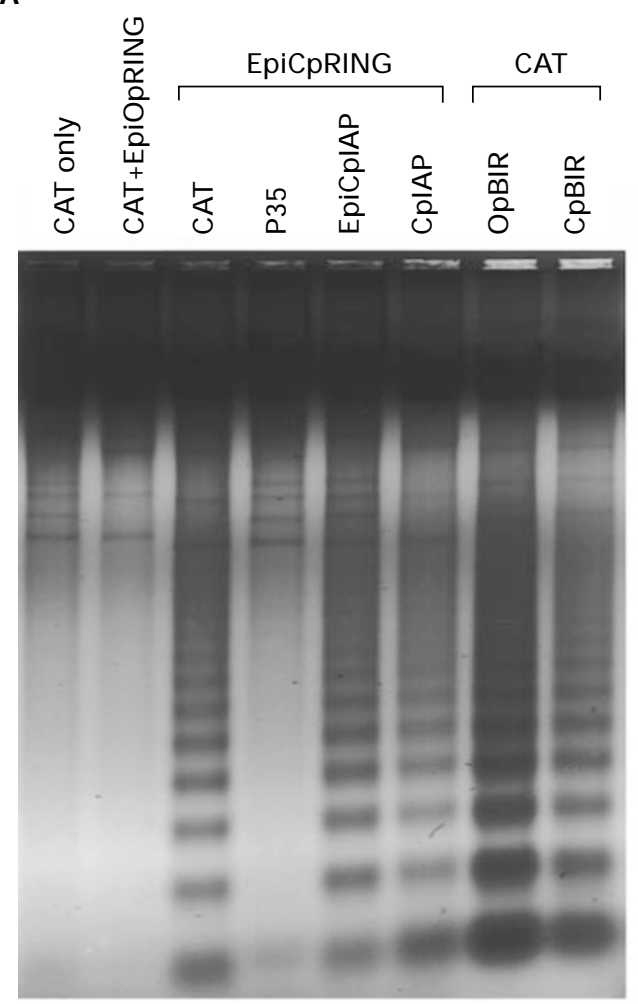

B

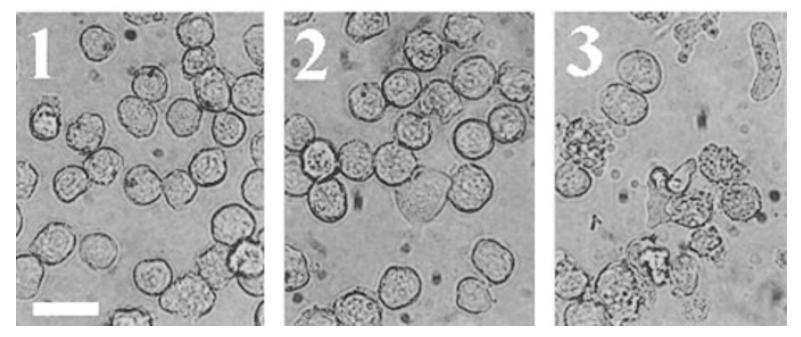

C

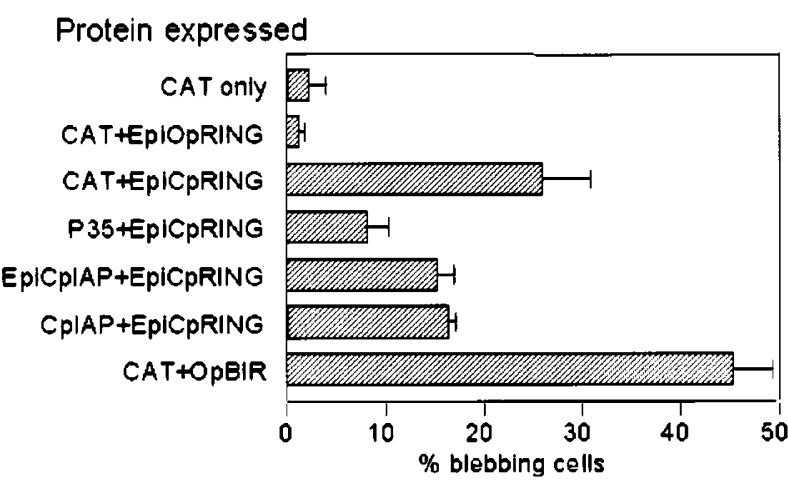

Figure 6 The RING finger region of CpIAP but not OpIAP induces apoptosis. (A) SF-21 cells were transfected with plasmids expressing the protein(s) indicated above each lane under heat shock promoter control. Cellular DNA was harvested at $24 \mathrm{~h}$ post-heat shock, separated by agarose gel electrophoresis, stained with ethidium bromide and visualized on a fluorimager. (B) SF-21 cells were heat shocked at $\mathrm{t}=0 \mathrm{~h}$ following cotransfection with plasmids expressing the following proteins under heat shock promoter control. Photographs were taken at $24 \mathrm{~h}$ post-heat shock: not shown). Thus, the epitope tag interfered with the antiapoptotic activity of DIAP1 $\beta$ in actinomycin D-treated cells.

\section{Baculovirus and Drosophila IAPs can inhibit Doom-induced apoptosis}

The entire Doom open reading frame was fused to the FLAG epitope, creating FlagDoom (also called FlagDoom(1-514) (Harvey et al, 1996)). Within $3 \mathrm{~h}$ post-heat shock, FlagDoom induced membrane blebbing and, at $8 \mathrm{~h}$ post-heat shock, nucleosomal laddering and extensive membrane blebbing was apparent (Figures 8A and 9), as described for FlagDoom (99-514) (Harvey et al, 1996). As previously described, full length baculovirus IAPs blocked FlagDoom-induced apoptosis as judged by the extent of laddering detected at $8 \mathrm{~h}$ postheat shock (Figure 8A) (Harvey et al, 1996). The baculovirus $\mathrm{BIR}$ and RING finger regions, transfected alone or together, were not able to block FlagDoom-induced apoptosis (Figure $8 A)$.

DIAP1 $\beta$ and EpiDIAP1 $\beta$ inhibited FlagDoom-induced apoptosis at $8 \mathrm{~h}$ post-heat shock as indicated by the reduction in nucleosomal laddering (Figure $8 \mathrm{~B}$ ) and membrane blebbing (Figure 9). DIAP1 $\beta$-BIR slowed but did not block FlagDoom-induced apoptosis as nucleosomal laddering was evident at $8 \mathrm{~h}$ (Figure 8B) and membrane blebbing was widespread by $8 \mathrm{~h}$ post-heat shock (Figure 9 ). EpiDIAP1 $\beta$-BIR had little effect on FlagDoom-induced apoptosis as laddering was marginally reduced (Figure 8B) and there was no effect on blebbing (data not shown). EpiDIAP1 $\beta$ and EpiDIAP1 $\beta$-BIR were detected at similar levels when coexpressed with FlagDoom (data not shown), indicating that removal of the RING finger did not effect the expression or stability of the DIAP1 constructs. DIAP1-RING did not inhibit FlagDoom-induced apoptosis nor did DIAP1RING alter the inhibitory effect of DIAP1-BIR (Figure 8B).

EpiDIAP2 but not untagged DIAP2 marginally reduced nucleosomal laddering induced by FlagDoom (Figure 8B) but both DIAP2 and EpiDIAP2 significantly reduced membrane blebbing at $8 \mathrm{~h}$ post-heat shock (Figure 9, data not shown for DIAP2). EpiDIAP2-BIR had no effect on FlagDoom-induced nucleosomal laddering and membrane blebbing (Figures 8B and 9). Both EpiDIAP2 and EpiDIAP2-BIR were difficult to detect in cells expressing FlagDoom (data not shown), indicating that these proteins were unstable in the apoptotic environment.

\section{Discussion}

Whereas full-length baculovirus IAPs block actinomycin Dand Doom-induced apoptosis, the BIR and RING finger regions did not block actinomycin $D$ or Doom-induced apoptosis when expressed alone or coexpressed in trans, indicating that the BIR and RING finger regions of these viral

chloramphenical acetyltransferase (CAT), (panel 1); EpiOpRING plus CAT, (panel 2); EpiCpRING plus CAT, (panel 3); Scale bar $25 \mu \mathrm{m}$. (C) The percentage of cells demonstrating blebbing and elongation induced by expression of the indicated constructs was determined at $24 \mathrm{~h}$ post-heat shock as described in Materials and Methods 
A
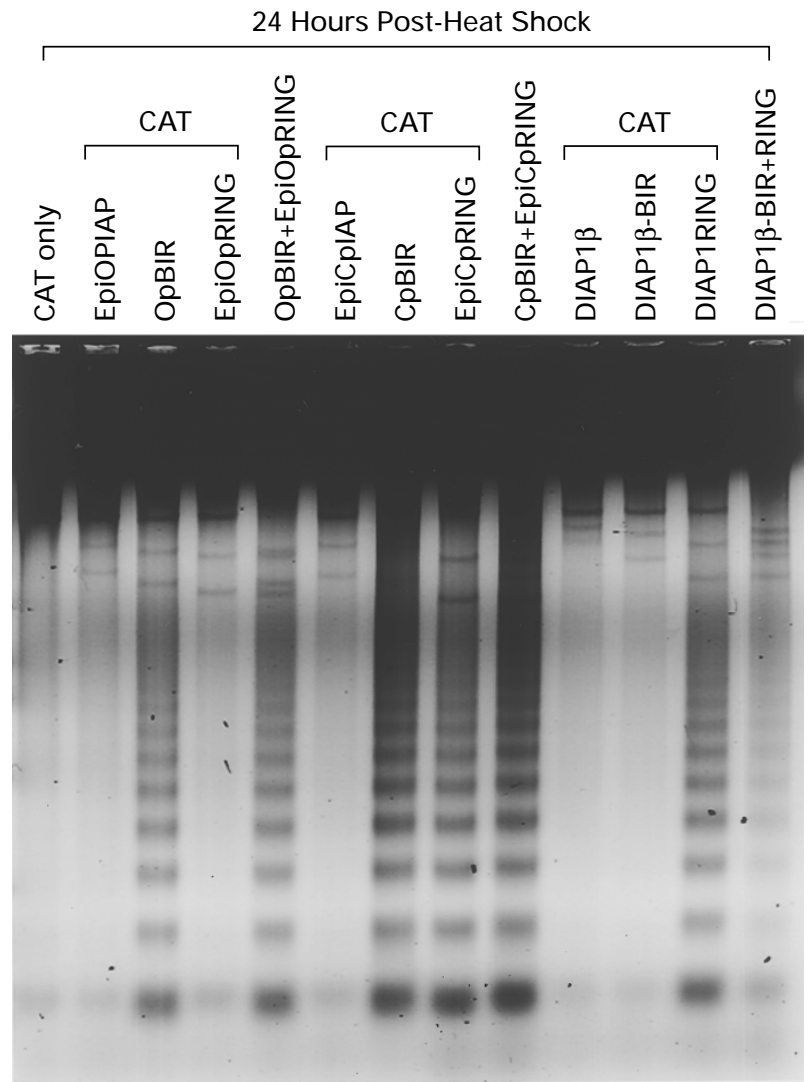

B

Protein expressed

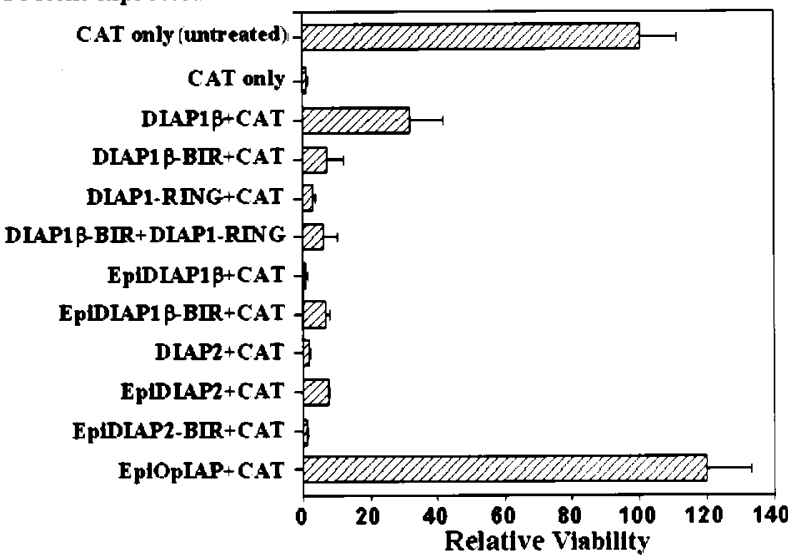

Figure 7 The RING finger region of DIAP1 induced apoptosis and DIAP1 $\beta$ inhibited actinomycin D-induced apoptosis. (A) SF-21 cells were transfected with plasmids expressing the protein(s) indicated above each lane under heat shock promoter control. CAT-expressing plasmids were used to balance concentrations of plasmids transfected into cells. Cellular DNA was harvested at $24 \mathrm{~h}$ post-heat shock, separated by agarose gel electrophoresis, stained with ethidium bromide and visualized on a fluorimager. (B) SF-21 cells expressing the indicated proteins were treated with actinomycin $D$ at $4 \mathrm{~h}$ postheat shock. Cell viability was determined $20 \mathrm{~h}$ later by the trypan blue exclusion assay. Viability was compared to untreated CAT-expressing cells counted at the time of actinomycin D treatment
IAPs must be covalently attached in order to block apoptosis (see Table 1 for a summary of the results). Although the BIR regions of the baculovirus IAPs physically interact with Doom (Harvey et al, 1996), the apoptotic activity of Doom was not reduced when coexpressed with BIRs alone or with the BIRs and RING finger. The interpretation of these data are complicated by the unexpected observation that expression of the baculovirus BIRs alone induced apoptosis in SF-21 cells. The BIRs may be inducing apoptosis by displacing endogenous cellular IAPs, thereby disrupting their antiapoptotic function; the lack of the RING finger may disrupt normal signaling exerted by endogenous IAPs.

DIAP1 $\beta$ was able to inhibit actinomycin D and Doominduced apoptosis, confirming its anti-apoptotic behavior. Removal of the RING finger from DIAP $1 \beta$ significantly reduced but did not abolish its anti-apoptotic activity, indicating that, as previously reported, the BIR region of DIAP1 can act to inhibit apoptosis (Hay et al, 1995). However, in the developing Drosophila eye, DIAP1-BIR is significantly more active than DIAP1, suggesting that the RING finger is acting as a negative regulator of DIAP1 activity (Hay et al, 1995). In SF-21 cells, removal of the RING finger from DIAP1 $\beta$ abolished its ability to block actinomycin D-induced apoptosis and reduced its ability to block Doom-induced apoptosis.

The difference in behavior of the DIAP1 RING finger region may be a result of the heterologous nature of the SF-21 cell assay system. The behavior of an exogenous protein in SF-

A
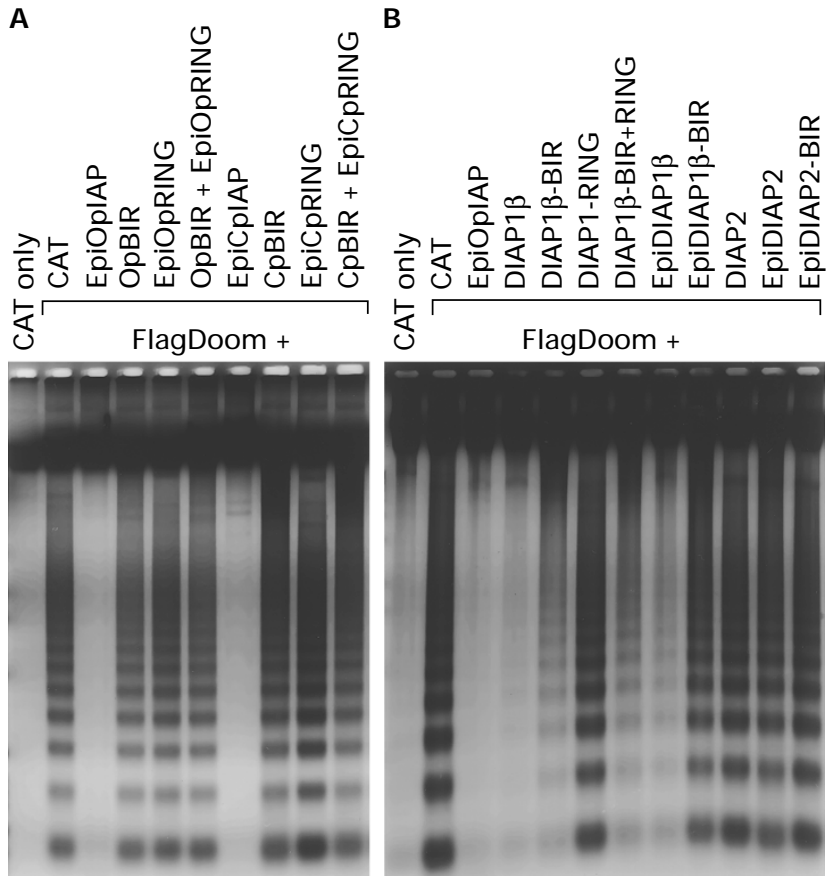

Figure 8 Inhibition of Doom-induced chromatin degradation by baculovirus and Drosophila IAPs. (A) and (B) SF-21 cells were transfected with plasmids expressing the protein(s) indicated above each lane under heat shock promoter control. CAT-expressing plasmids were used to balance concentrations of plasmids transfected into cells. Cellular DNA was harvested at $8 \mathrm{~h}$ post-heat shock, separated by agarose gel electrophoresis, stained with ethidium bromide and visualized on a fluorimager 
21 cells may differ from that in the cell lineage or species in which it is normally expressed. An additional consideration is that we were unable to express DIAP1 from its first methionine, as any expressed protein was rapidly degraded. Both full-length DIAP1 (translated from the first methionine) and a truncated form of DIAP1 lacking the RING finger were rapidly degraded into small peptides and
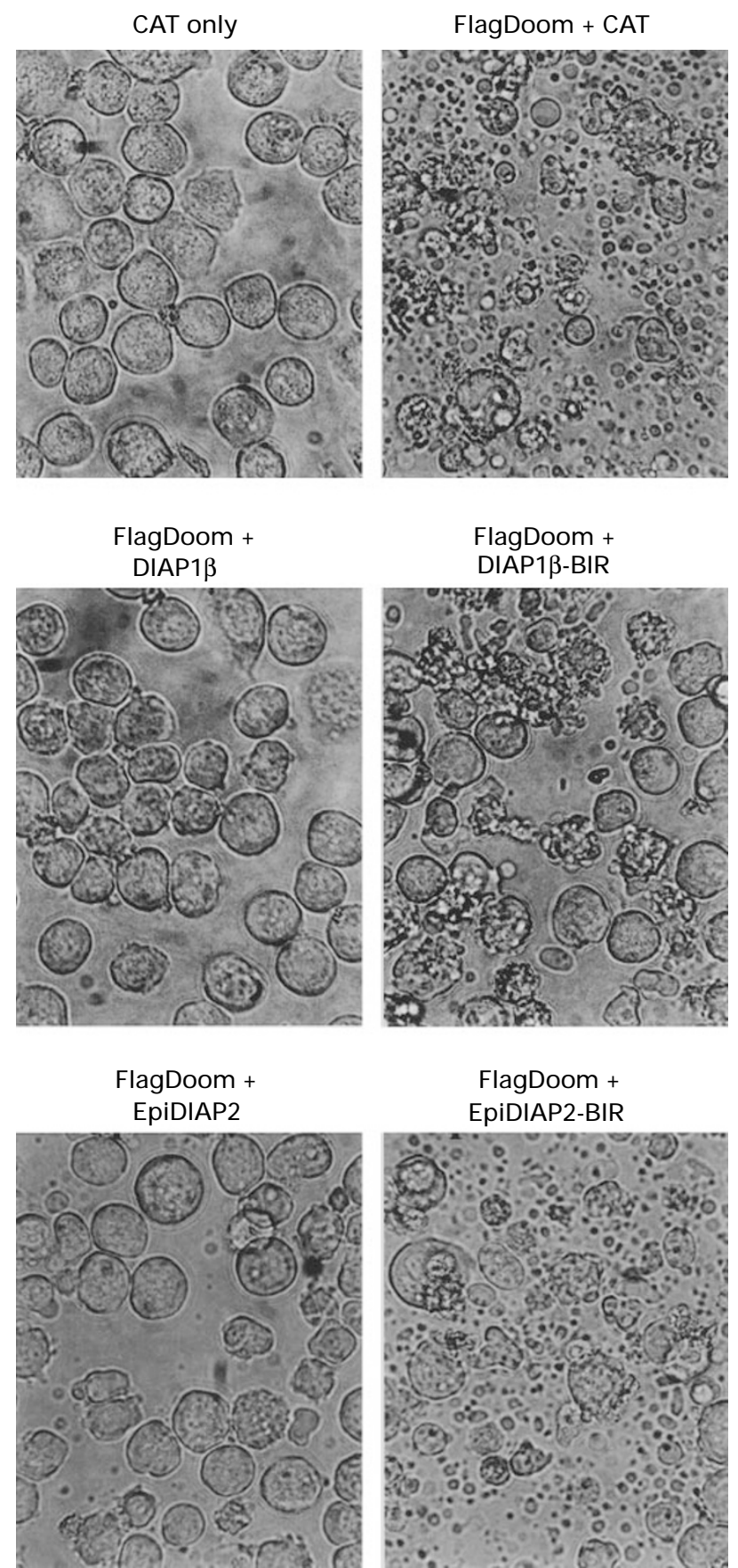

Figure 9 Inhibition of Doom-induced membrane blebbing by Drosophila IAPs. SF-21 cells were transfected with plasmids expressing the protein(s) indicated above each photograph under heat shock promoter control. CATexpressing plasmids were used to balance concentrations of plasmids transfected into cells. Photographs were taken at $8 \mathrm{~h}$ post-heat shock demonstrated no anti- or pro-apoptotic activity (data not shown). The possibility exists that full-length DIAP1 would be more stable in Drosophila and behave differently; more information is needed regarding the behavior of the full-length and truncated forms of DIAP1 in the context of Drosophila cells.

Epi-tagged DIAP2 was able to inhibit FlagDoom-induced membrane blebbing but not nucleosomal laddering. In cells induced to undergo apoptosis by FlagDoom, membrane blebbing emerges at $2-3 \mathrm{~h}$ post-heat shock while significant chromatin degradation is not detectable until $8 \mathrm{~h}$ post-heat shock (Harvey et al, 1996). When FlagDoom was coexpressed with EpiDIAP2, nucleosomal laddering was reduced only slightly at $8 \mathrm{~h}$ post-heat shock. Membrane blebbing was delayed and was not evident until $8 \mathrm{~h}$, at which time it was greatly reduced as compared to cells expressing FlagDoom alone. It is likely that these differences were due to the low levels of EpiDIAP2 in the presence of FlagDoom. We had difficulty detecting EpiDIAP2 (and EpiDIAP2-BIR) in cells expressing FlagDoom, presumably due to instability of DIAP2 in the SF-21 apoptotic environment (data not shown). The level of EpiDIAP2 may not be sufficient to inhibit FlagDoom-induced nucleosomal laddering but be sufficient to inhibit FlagDoom-induced membrane blebbing. The low EpiDIAP2 expression in the SF-21 apoptotic environment is consistent with the observed lack of protection against actinomycin D-induced apoptosis; inhibition of actinomycin D-induced apoptosis may require higher levels of protein expression.

The RING finger regions of CpIAP and DIAP1 also induced apoptosis when expressed separately from the BIR region. It is unknown why the RING finger truncation of OpIAP did not behave similarly because the amino acid $219-268$ region of OpIAP, which includes the RING finger, is $58 \%$ and $56 \%$ identical to the corresponding regions of DIAP1 and CpIAP, respectively. In addition, a functional hybrid IAP can be created by replacing the RING finger of CpIAP with the RING finger of OpIAP, indicating that the RING finger regions of OpIAP and CpIAP are interchangeable (Clem and Miller, 1994). However, the region encompassing amino acids $226-275$ of CpIAP is $70 \%$ identical to the corresponding region of DIAP1 but only $56 \%$ identical to OpIAP, suggesting that the RING fingers of CpIAP and DIAP1 are more similar in secondary and tertiary structure than that of OpIAP and may function optimally in different apoptotic pathways. The variation in the behavior of the RING fingers may reflect the ability of the RING fingers to function in different pathways in the cell. The fact that none of the IAPS tested have evolved specifically to function in SF-21 cells (although they can block apoptosis in this cell line) makes interpretation of these specific effects difficult.

AcMNPV carries two IAP homologues, AcIAP1 and AclAP2, which apparently are not sufficient to block viralinduced apoptosis in SF-21 cells as P35 mutant viruses rapidly undergo apoptosis upon infection of SF-21 cells (Ayres et al, 1994; Braunagel et al, 1992; Clem et al, 1991; Clem and Miller, 1993). OpMNPV carries four IAP homologues (Ahrens et al, 1997; Birnbaum et al, 1994). While OpIAP, also called OpIAP-3, has been shown to be an apoptotic inhibitor (Birnbaum et al, 1994), the role of the 
Table 1 Apoptotic activities of baculovirus and Drosophila IAPs in SF-21 cells

\begin{tabular}{|c|c|c|c|c|}
\hline \multirow[b]{2}{*}{ IAP Domain } & \multirow[b]{2}{*}{$\begin{array}{l}\text { Induced } \\
\text { apoptosis }\end{array}$} & \multicolumn{3}{|c|}{ Inhibited } \\
\hline & & $\begin{array}{c}\text { Actinomycin D- } \\
\text { induced apoptosis }\end{array}$ & $\begin{array}{c}\text { Doom-induced } \\
\text { chromatin degradation }\end{array}$ & $\begin{array}{c}\text { Doom-induced } \\
\text { membrane blebbing }\end{array}$ \\
\hline Full $^{\mathrm{a}}$ & $\mathrm{No}^{\mathrm{e}}$ & $Y_{e s}{ }^{d}$ & Yes & Yes \\
\hline $\mathrm{BIRs}^{\mathrm{b}}$ & Yes & No & No & No \\
\hline $\mathrm{RING}^{\mathrm{c}}$ & Yes $^{f}$ & No & No & No \\
\hline \multicolumn{5}{|l|}{ DIAP1 $\beta$} \\
\hline BIRs & No & No & $Y_{e s}^{g}$ & $\mathrm{Yes}^{\mathrm{g}}$ \\
\hline RING & Yes & No & No & No \\
\hline \multicolumn{5}{|l|}{ DIAP2 } \\
\hline Full & No & No & No & Yes $^{\mathrm{g}}$ \\
\hline BIRs & No & No & No & No \\
\hline RING & $N D^{h}$ & ND & ND & ND \\
\hline
\end{tabular}

${ }^{a}$ Full, full-length IAP. ${ }^{b}$ BIRs, region containing two or three BIR motifs. ${ }^{c}$ RING, RING finger domain. dYes indicates that either the untagged or Epi-tagged or both versions of the domain demonstrated activity. ${ }^{\mathrm{e}} \mathrm{No}$ indicates that no activity was observed for the untagged and Epi-tagged versions of each domain. ${ }^{\mathrm{f}}$ The RING finger of

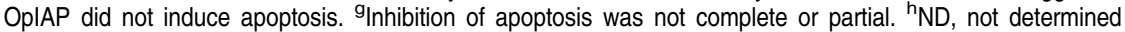

additional viral IAPs remains to be determined. It is possible that these viruses encode multiple IAPs so that a variety of apoptotic signaling pathways can be silenced, thus increasing the host and/or tissue range of the virus. Likewise baculovirus IAPs have maximized their protective abilities by coevolution of the BIRs and RINGs. It is unlikely that the RING finger plays a regulatory role in the viral life cycle; it would not be advantageous for the virus to downregulate its anti-apoptotic response. Thus during the evolution of baculoviruses, they have retained the IAP RING finger region to enhance protection against the cellular apoptotic response.

Analogous to the baculoviruses, the presence of multiple IAP homologues in higher eukaryotes suggests that those proteins may have evolved somewhat different functions so that they function optimally in different apoptotic signaling pathways. Although most have been shown to inhibit apoptosis to varying degress, the actual physiological role of these IAPs remains to be established. The eukaryotic IAPs possibly have evolved to regulate a variety of biological activities, including cell fate and cell cycle. The BIRs and RINGs would have evolved so that the anti-apoptotic activity is regulated and not constitutive. Thus for at least some cellular IAPs, the BIRs and RINGs would have evolved independently such that the BIR is anti-apoptotic while the RING counters the activity of the BIR. The balance between the activities of the BIRs and RINGs of eukaryotes could depend on the cellular environment and the availability of interacting factors that reside in one or more apoptotic pathways. As the cellular targets of the BIRs and RINGs are determined, the role and regulation of the IAPs should become clearer.

\section{Materials and Methods}

\section{Expression plasmid construction}

To construct pHSEpiOpIAPNrul, the OpIAP open reading frame in pHSOpIAPNrul (described in Clem and Miller, 1994) was epitope- tagged at the amino-terminal Aval site by insertion of DNA encoding the sequence RYPYDVPDYARA. The sequence YPYDVPDYA constitutes the hemagglutinin epitope, HA.11. pHSEpiOpIAPdel was created by deleting the PmIl-Pmll fragment, which overlaps the RING finger domain, creating a frameshift starting at amino acid 249 of OpIAP and continuing an additional 27 amino acids. pHSEpiOpBIR and pHSOpBIR was created by deleting from pHSEpiOpIAPNrul and pHSOpIAPNrul, respectively, the region between the Nrul site at amino acid 199 and the Clal site in the $3^{\prime}$ untranslated region of OpIAP, thereby creating a stop codon after amino acid 199. pHSEpiOpRING was constructed by deleting from pHSEpiOpIAPNrul the region between the Apal site, which resides at the $3^{\prime}$ end of the HA epitope tag, and Nrul at amino acid 198, fusing amino acid 198 in frame to the HA epitope tag. pHSEpiOpRING2, which encodes a smaller EpiOpRING, was constructed by PCR amplifying a region of pHSOpIAPNrul using the oligo 5'-TCCCCCCGGGCCCGGCTGTGCAAGATTTGCC-3' and the T3 oligo followed by digestion with Smal and Clal. The resulting PCR fragment, which contains a Smal site at the $5^{\prime}$ end of the RING finger coding region and a Clal site at the $3^{\prime}$ end of the $3^{\prime}$ untranslated region, was used to replace the Smal-Clal region of pHSEpiOpIAPNrul.

pHSEpiCpIAP was created by replacing the entire coding region and $3^{\prime}$ untranslated region of pHSEpiOpIAPNrul downstream of the epitope tag with the entire coding region and $3^{\prime}$ untranslated region of CpIAP derived from pHSCpIAP (described in Clem and Miller, 1994). pHSCpBIR and pHSEpiCpBIR were created by cutting pHSCpIAP and pHSEpiCpIAP, respectively, with BstBI, blunt ending with Klenow and religating the linear vectors. pHSEpiCpRING was constructed by cutting pHSCpIAP with BstBI, blunt ending with Klenow, and cutting with Pstl. The resulting fragment, which contains the RING finger and $3^{\prime}$ untranslated region of CpIAP was used to replace the coding region and $3^{\prime}$ untranslated region of OpIAP in pHSEpiOpIAPNrul.

pHSEpip35 was constructed by cutting pHSp35VI+ (described in Clem and Miller, 1994) with Pstl and EcoRI, removing the $5^{\prime}$ and $3^{\prime}$ overhangs, and blunt-end ligating into pHSEpiOpIAPNrul digested with Smal and Clal. The modified Pstl end of p35 is in frame with the HA epitope tag and the p35 coding sequence replaces that of OpIAP. pGMR-DIAP1 $\beta$-ORF was constructed by inserting the EcoRI/filledin Notl fragment of pBSDIAP1 $\beta$-ORF (which contains nucleotides 534-1741 of the DIAP1 cDNA (Hay et al, 1995) into the EcoRI/Stul site of pGMR. pHSDIAP1 $\beta$ was constructed by inserting the Hindlll/ 
EcoRI fragment from pGMR-DIAP1 $\beta$-ORF containing the DIAP1 ORF starting from the second methionine and the HSP70 $3^{\prime}$ untranslated region in the $B g / l$ site of $\mathrm{pHSP70PL}$. pHSDIAP1 $\beta$-BIR was constructed by inserting the HindlII/ECoRI fragment from pGMRDIAP1 $\beta$-BIR containing the DIAP1-BIR coding region (starting at nucleotide 534 and ending at 1576 of the DIAP1 cDNA (Hay et al, 1995 ) and the HSP70 $3^{\prime}$ untranslated region into the Bg/ll site of pHSP70PL. pHSDIAP1-RING was constructed by inserting the HindllI/ EcoRI fragment from pGMRDIAP1-RING containing the DIAP1-RING finger coding region and the HSP70 $3^{\prime}$ untranslated region into the Bglll site of pHSP70PL.

pHSEpiDIAP1 $\beta$-BIR was constructed by replacing the Apal/Pmll region of pHSEpiOpIAPNrul containing the OpIAP ORF and part of the HSP70 $3^{\prime}$ untranslated region with the Dral fragment of pHSDIAP1 $\beta$ BIR, which contains nucleotides 551-1576 of the DIAP1 CDNA and part of the HSP70 $3^{\prime}$ untranslated region, so that the DIAP1 ORF is in frame with the HA epitope tag. PHSEpiDIAP1 $\beta$ was constructed by replacing the Clal/Pstl region of pHSEpiDIAP1 $\beta$-BIR with the Clal/Pstl region of pGMR-DIAP1 $\beta$-ORF so that the Epi-tagged DIAP1-ORF has an intact RING finger and a HSP70 $3^{\prime}$ untranslated region.

pHSDIAP2 was constructed by inserting the EcoRl fragment of pBSDIAP2-ORF, containing the DIAP2 ORF, into the Bgll site of pHSP70. pHSEpiDIAP2 was constructed by PCR of pBSDIAP2-ORF using the oligo 5'-CGCGGATCCCCCGGGTGACGGAGCTGGGCCTGGAGCTGG-3' and the T7 oligo followed by digestion with Smal and Notl. The resulting PCR fragment, which contains a Smal site at the $5^{\prime}$ end of the DIAP2 coding region and a filled-in Notl site at the $3^{\prime}$ end, was used to replace the Smal-Pmll region of pHSEpiOpIAPNrul. pHSEpiDIAP2-BIR was constructed by inserting a $X$ bal amber codon linker (New England Biolabs) at the Agel site (amino acid 397) of pHSEpiDIAP2.

pHSFlagDoom was constructed by PCR of pBSDoom1 (Harvey et al, 1996) using the oligo 5'-CGCGGATCCCCCGGGCGGACGACGAGCAATTC-3' and the T7 oligo followed by digestion with Smal and Dral. The resulting PCR fragment, which contains a Smal site at the $5^{\prime}$ end of the Doom coding region and a Dral site at the $3^{\prime}$ end of the $3^{\prime}$ untranslated region, was used to replace the $S$ mal-Pmll region of pHSEpiOpIAPNrul.

\section{Cell culture and transfections}

S. frugiperda (fall armyworm) IPLB-SF-21 (SF-21) cells (Vaughn et al, 1977) were maintained as previously described (O'Reilly et al, 1992). Transfections were carried out as previously described (O'Reilly et al, 1992), except transfections were performed on $0.5 \times 10^{6} \mathrm{SF}-21$ cells in $35 \mathrm{~mm}$ tissue culture plates and the transfection mixture consisted of $2.5 \mu \mathrm{l}$ of lipofectin (Gibco-BRL) and $1.0 \mu \mathrm{g}$ of each plasmid in $0.5 \mathrm{mls}$ incomplete TC-100. After transfection, plates were incubated $20 \mathrm{~h}$ at $27^{\circ} \mathrm{C}$. Plates were heat shocked as previously described (Clem and Miller, 1994).

\section{Microphotography and quantitation of apoptosis}

Phase contrast photography of transfected cells was performed on an Olympus IX50 inverted microsope equipped with a PM-10AK camera. For actinomycin $\mathrm{D}$ experiments, the percent of cells undergoing apoptosis was performed as previously described (Clem and Miller, 1994) except cells were transfected using lipofectin and the final concentration of actinomycin $D$ was $500 \mathrm{ng} / \mathrm{ml}$. Note that the actual number of viable cells was increased approximately twofold due to an artifact involving an increased sensitivity of non-actinomycin D-treated cells to scraping, as previously described (Clem and Miller, 1994). To determine the percent of cells undergoing apoptosis at 8 and $24 \mathrm{~h}$ postheat shock due to BIR or RING expression, photographs were taken at the indicated times of three separate transfections. The percentage of cells undergoing apoptosis for a given photograph was determined by counting the number of cells that displayed membrane blebbing and/or elongation and dividing by the total number of cells in the photograph.

\section{Nucleosomal ladder preparation}

For nucleosomal ladder preparation, $0.5 \times 10^{6}$ transfected SF-21 cells in $35 \mathrm{~mm}$ tissue culture plates were harvested at 8 or $24 \mathrm{~h}$ post-heat shock by scraping into the medium. Cells were pelleted at $2000 \times g$ and resuspended in 0.4 M Tris- $\mathrm{Cl}, \mathrm{pH}$ 7.5, 0.1 M EDTA, then SDS and proteinase $\mathrm{K}$ were added to a final concentration of $0.1 \%$ and $200 \mu \mathrm{g} /$ $\mathrm{ml}$, respectively. After $12-20 \mathrm{~h}$ at room temperature, lysates were extracted once with phenol/chloroform/isoamyl alcohol (25:24:1) and precipitated with 2.5 volumes of ethanol and 0.1 volumes of $5 \mathrm{M} \mathrm{NaCl}$. After centrifugation at $12000 \times g$, DNA pellets were washed with $70 \%$ ethanol, dried and resuspended in $30 \mu 10 \mathrm{mM}$ Tris-acetate, $\mathrm{pH} 8.0$, $1 \mathrm{mM}$ EDTA, $20 \mu \mathrm{g} / \mathrm{ml}$ RNase A, $0.025 \%$ bromophenol blue, $3.0 \%$ glycerol. A $1.2 \%$ agarose gel was partially submerged in $0.04 \mathrm{M}$ Trisacetate, $\mathrm{pH}$ 8.2, $1 \mathrm{mM}$ EDTA, and wells were half-filled with running buffer. $20 \mu \mathrm{l}$ of each DNA sample was loaded, electrophoresed at 5 volts/cm for $15 \mathrm{~min}$, the gel was submerged in running buffer and electrophoreses was continued for $2 \mathrm{~h}$. The gel was stained in $20 \mu \mathrm{g} / \mathrm{ml}$ ethidium bromide and visualized on a Molecular Dynamics Fluorimager with no filter.

\section{Immunoblotting}

Transfected cells were harvested at $4 \mathrm{~h}$ post-heat shock and pelleted at $500 \times g$. Cells were lysed in $50 \mu$ l of $0.5 \mathrm{M}$ Tris-Cl, pH 6.8, $10 \%$ SDS, $10 \%$ glycerol, $1.43 \mathrm{M}$ 2-mercaptoethanol, $0.001 \%$ bromophenol blue. $10 \mu \mathrm{l}$ of total cell lysates were heated to $95^{\circ} \mathrm{C}$ for $5 \mathrm{~min}$, separated on $12 \%$ SDS-PAGE and transferred to Immobilon P membranes (Millipore). Epi-tagged constructs were detected with 1:10 000 dilution of rabbit anti-HA.11 polyclonal antisera (Berkeley Antibody Co.) and 1:20 000 dilution of goat anti-rabbit IgG HRP conjugate (Promega). Immunoblots were visualized with the Enhanced Chemiluminescence (ECL) Western Blotting System (Amersham).

\section{Acknowledgements}

We thank BA Hay and GM Rubin for the DIAP clones. We thank the entire LK Miller lab for their patience and assistance. We thank the staff of the Molecular Genetics Instrumentation Facility for DNA sequencing and assistance with the Fluorimager. This research was supported in part by Public Health Service grant Al38262 from the National Institute of Allergy and Infectious Diseases to LKM.

\section{References}

Ahrens CA, Russell RR, Funk CJ, Evans J, Harwood Sand Rohrmann GF (1997) The sequence of the Orgyia pseudotsugata multinucleocapsid nuclear polyhedrosis virus genome. Virology 229: 381-399

Arends MJ and Wyllie AH (1991) Apoptosis: mechanisms and role in pathology. Int. Rev. Exp. Pathol. 32: 223-254

Ayres MD, Howard SC, Kuzio J, Lopez-Ferber M and Possee RD (1994) The complete DNA sequence of Autographa californica nuclear polyhedrosis virus. Virology 202: 586-605

Birnbaum MJ, Clem RJ and Miller LK (1994) An apoptosis-inhibiting gene from a nuclear polyhedrosis virus encoding a polypeptide with $\mathrm{Cys} / \mathrm{His}$ sequence motifs. J. Virol. 68: 2521-2528 
Braunagel SC, Daniel KD, Reilly LM, Guarino LA, Hong T and Summers MD (1992) Sequence, genomic organization of the EcoRI-A fragment of Autographa californica nuclear polyhedrosis virus, and identification of a viral-encoded protein resembling the outer capsid protein VP8 of rotavirus. Virology 191: $1003-1008$

Bump NJ, HackettM, Hugunin M, Seshagiri S, Brady K, Chen P, Ferenz C, Franklin S, Ghayur T, Li P et al (1995) Inhibition of ICE family proteases by baculovirus antiapoptotic protein $\mathrm{p35}$. Science 269: 1885-1888

Clem RJ, Fechheimer M and Miller LK (1991) Prevention of apoptosis by a baculovirus gene during infection of insect cells. Science 254: 1388-1390

Clem RJ, Hardwick JM and Miller LK (1996) Anti-apoptotic genes of baculoviruses. Cell Death Differ. 3: 9-16

Clem RJ and Miller LK (1993) Apoptosis reduces both the in vitro replication and the in vivo infectivity of a baculovirus. J. Virol. 67: 3730-3738

Clem RJ and Miller LK (1994) Control of programmed cell death by the baculovirus genes $p 35$ and iap. Mol. Cell. Biol. 14: 5212-5222

Crook NE, Clem RJ and Miller LK (1993) An apoptosis-inhibiting baculovirus gene with a zinc finger-like motif. J. Virol. 67: 2168-2174

Dorn R, Krauss V, Reuter Gand Saumweber H(1993) The enhancer of position-effect variegation of Drosophila, $E$ (var)3-93D, codes for a chromatin protein containing a conserved domain common to several transcriptional regulators. Proc. Natl. Acad. Sci. USA. 90: 11376-11380

Duckett CS, Nava VE, Gedrich RW, Clem RJ, Van Dongen JL, Gilfillan MC, Shiels H, Hardwick JM and Thompson CB (1996) A conserved family of cellular genes related to the baculovirus iap gene and encoding apoptosis inhibitors. EMBO J. 15: $2685-2694$

Freemont PS (1993) The RING finger: a novel protein sequence motif related to the zinc finger. Ann. NY Acad. Sci. 684: 174-192

Gerasimova TI, Gdula DA, Gerasimov DV, Simonova O and Corces VG (1995) A Drosophila protein that imparts directionality on a chromatin insulator is an enhancer of position-effect variegation. Cell 82: 587-597

Harvey AJ, Bidwai AP and Miller LK (1996) Doom, a product of the Drosophila $\bmod (m d g 4)$ gene, induces apoptosis and binds to baculovirus inhibitor of apoptosis proteins. In Press

Hay BA, Wassarman DA and Rubin GM (1995) Drosophila homologs of baculovirus inhibitor of apoptosis proteins function to block cell death. Cell 83: 1253-1262

Hay BA, Wolff T and Rubin GM (1994) Expression of baculovirus P35 prevents cell death in Drosophila. Development 120: 2121-2129
Kamita SG, Majima K and Maeda S (1993) Identification and characterization of the p35gene of Bombyx morinuclear polyhedrosis virus that prevents virus-induced apoptosis. J. Virol. 67: 455-463

Liston P, Roy N, Tamai K, Lefebvre C, Baird S, Cherton-Horvat G, Farahani R, McLean M, Ikeda JE, MacKenzie A and Korneluk RG (1996) Suppression of apoptosis in mammalian cells by NAIP and a related family of IAP genes. Nature 379: $349-353$.

O'Reilly DR, Miller LK and Luckow VA (1992) Baculovirus expression vectors: a laboratory manual. New York: W.H. Freeman \& Co.

Rabizadeh S, LaCount DJ, Friesen PD and Bredesen DE (1993) Expression of baculovirus $p 35$ gene inhibits mammalian neural cell death. J. Neurochem. 61: $2318-2321$

Rothe M, Pan MG, Henzel WJ, Ayres TM and Goeddel DV (1995) The TNFR2-TRAF signaling complex contains two novel proteins related to baculoviral inhibitor of apoptosis proteins. Cell 83: $1243-1252$

Roy N, Mahadevan MS, McLean M, Shutler G, Yaraghi Z, Farahani R, Baird S, Besner-Johnston A, Lefebvre C, Kang X et al (1995) The gene for neuronal apoptosis inhibitory protein is partially deleted in individuals with spinal muscular atrophy. Cell 80: 167-178

StellerH(1995) Mechanisms and genes of cellular suicide. Science 267: 1445-1449

Sugimoto A, Friesen PD and Rothman JH (1994) Baculovirus p35 prevents developmentally programmed cell death and rescues a ced-9 mutant in the nematode Caenorhabditis elegans. EMBO J. 13: 2023-2028

Thompson CB (1995) Apoptosis in the pathogenesis and treatment of disease. Science 267: 1456-1462

Uren AG, Pakusch M, Hawkins CJ, Puls KL and Vaux DL (1996) Cloning and expression of apoptosis inhibitory protein homologs that function to inhibit apoptosis and/or bind tumor necrosis factor receptor-associated factors. Proc. Natl. Acad. Sci. USA. 93: 4974-4978

Vaughn JL, Goodwin RH, Tompkins GJ and McCawley P (1977) The establishment of two cell lines from the insect Spodoptera frugiperda (Lepidoptera; Noctuidae). In Vitro. 13:213-217

Wyllie AH, Kerr JFR and Currie AR (1980) Cell death: the significance of apoptosis. Int. Rev. Cytol. 68: 251-306

Xue D and Horvitz HR (1995) Inhibition of the Caenorhabditis elegans cell-death protease CED-3 by a CED-3 cleavage site in baculovirus p35 protein. Nature $377: 248-251$ 